\title{
Protective Effect of Grape Seed Oil on Hypercholesterolemia in Rats
}

\author{
Reda Ahmed Mokhtar*, Nefisa Hassan El-Banna, Mohammed Hamdy Haggag \\ Nutrition and Food Science Department, Faculty of Home Economics, Helwan University, Cairo, Egypt \\ Email address: \\ Redamokhtar@yahoo.com (R. A. Mokhtar) \\ ${ }^{*}$ Corresponding author

\section{To cite this article:} \\ Reda Ahmed Mokhtar, Nefisa Hassan El-Banna, Mohammed Hamdy Haggag. Protective Effect of Grape Seed Oil on Hypercholesterolemia \\ in Rats. International Journal of Nutrition and Food Sciences. Vol. 5, No. 5, 2016, pp. 310-317. doi: 10.11648/j.ijnfs.20160505.11
}

Received: July 3, 2016; Accepted: July 13, 2016; Published: August 4, 2016

\begin{abstract}
This study was carried out to investigate that the effect of grape seed oil (GSO) on Hypercholesterolemia in rats. Thirty-five rats were divided into 5 groups, group 1 was given the basal diet as a negative control group (-ve), group 2 was given the basal diet with GSO instead of soybean oil as a negative control for GSO. Groups (3, 4 and 5) were fed on high cholesterol diet (HCD) (1\% cholesterol powder and $0.5 \%$ bile salt for 8 weeks), Group 3 was +ve control, group 4 and 5 were treatment groups which received GSO $2 \%$ and $4 \%$ daily with HCD. The results of this study indicated that the GSO caused an improvement in the blood lipids especially 4\% GSO. The 4\% GSO decreased serum TC, TG, LDL-c and VLDL significantly $(\mathrm{P}<0.05)$, and caused a significant increase in HDL-C level. Also, 2\% GSO decreased TG, LDL-C and VLDL significantly (P $<0.05)$, whereas the level of HDL-C showed significant increases. Subsequently, GSO enhanced the lipid ratios: atherogenic coefficient (AC), cardiac risk ratio (CRR), LDL-c to HDL-c ratio and atherogenic index of plasma (AIP). Moreover, the serum, liver function (AST, ALT and ALP) levels also, enhanced in the GSO groups. However, 4\% GSO led to significant decrease in serum MDA and elevated serum GST. Otherwise, histopathological examination showed enhanced in the heart and aorta of rats compared with the +ve control group. This study indicates that GSO effective in lowering total cholesterol, triglyceride and LDL-c and increasing HDL-c. Therefore, GSO have hypocholesterolemic effect and might be effective to protect against the risk of CVD.
\end{abstract}

Keywords: Grape Seed Oil, GSO, Lipid Profile, Cholesterol, Triglyceride, HDL

\section{Introduction}

Grapes are one of the most fruits consumed widely worldwide and have considerable importance for their medicinal and nutritive value for thousands of years [1]. Grape seed oil (GSO) is a vegetable oil extracts from grape seeds, which contains about $7-20 \%$ oil [2]. GSO has a slightly taste also its often used with salads, frying and mayonnaise. Grape seed oil has high levels of unsaturated fatty acids (UFA) approximately 85 to $90 \%$ particularly linoleic acid (C18:2) [3], oleic acid (C18:1) and a little amount of linolenic acid (C18:3) and palmitoleic acid (C16:1) [4]. Moreover, linoleic acid is the main component in the GSO with more than $70 \%$ and oleic acid about $15 \%$ in the oil. On the other hand, the saturated fatty acids consist of $10 \%$, which are mainly palmitic (16:0) and stearic (18:0) [5].
Dietary fats and oils are known to affect plasma lipid profile and play a vital role in the development of atherosclerosis, heart disease and cancer which are the main causes of death. Several studies have shown that saturated fats increase total cholesterol (TC) and LDL-c levels in plasma, but, the dietary PUFA decrease them [6]. Grape seed oil (GSO) and its extract have been recently shown to have many health properties due to its contents of important bioactive compounds including polyphenols, flavonoids, procyanidins, proanthocyanidins, minerals and vitamins [7]. In addition, GSO contains high levels of UFA and low levels of SFA, as well as, high percentage of linoleic acid. It also not contains cholesterol or trans-fatty acids. Thence, it has been reported in many studies as hypocholesterolemic agent [8].

On the other hand, GSO is a good source of important bioactive components including: catechin, epicatechein, 
gallic acid and procyanidins. As well as, its contains tocopherols and tocotrienols which protect the body cells against free-radical damage. The phenolic compounds and antioxidants in the GSO act to decrease oxidative stress that contributes to the pathogenesis of hepatotoxicity [9]. Furthermore, GSO contains a high percentage of proanthocyanidins, which are natural antioxidants with strong antiradical activity [10]. Moreover, GSO may improve inflammatory status and insulin resistance in human [11]. It can act as effective alternative medicine to protect against diabetes [12]. Grape seed oil also has been reported to decrease plasma triglycerides, cholesterol, and LDL-c levels [13]. So, the aim of the present study was to investigate the effect of grape seed oil on hypercholesterolemia in rats fed on high cholesterol diet.

\section{Material and Methods}

\subsection{Materials}

\subsubsection{Animals}

Thirty-five male albino rats weighing approximately 100$120 \mathrm{~g}$ were obtained from the animal house colony of Vacsera, Helwan, Egypt and were housed in well aerated cages under hygienic condition.

\subsubsection{Chemicals}

Casein, all vitamins, minerals, cellulose and cholesterol powder were purchased from El-Gomhoria Pharmaceutical Company, Cairo, Egypt.

\subsubsection{Grape Seeds}

Grape seeds were obtained from Agricultural Research Center Giza, Egypt.

\subsubsection{Kits}

Kits required for biochemical analysis were purchased from Gamma Trade Company for Pharmaceutical.

\subsection{Methods}

\subsubsection{Extraction of Grape Seed Oil (GSO)}

Approximately $10 \mathrm{~g}$ of grape seed were extracted in a Soxhlet Apparatus for $20 \mathrm{~h}$ with hexane, according to Gómez et al., (1996) [14]. The obtained oil was dried in an anhydrous sodium sulfate column and pre-concentrated under reduced pressure to remove all the solvent.

\subsubsection{Determination of Phenolic Compounds}

The phenolic compounds were analyzed using HPLC equipped with a UV detector and an $\mathrm{C} 18$ column $(250 \mathrm{~mm} \times$ $4.6 \mathrm{~mm}$ ) with particle size of $100 \mathrm{~A}$. The eluting system consisted of $2.0 \%(\mathrm{v} / \mathrm{v})$ acetic acid as solvent $\mathrm{A}$ and acetonitrile as solvent $\mathrm{B}(\mathrm{A}: \mathrm{B}=90: 10)$ in isocratic condition. The solutions of the standards and the extract phenolics were filtered through a $0.45 \mu \mathrm{m}$ syringe filter. The operating conditions were: column temperature, $25^{\circ} \mathrm{C}$; injection volume, $10 \mu \mathrm{L}$; detection wavelength, $280 \mathrm{~nm}$ and 1.2 $\mathrm{mL} / \mathrm{min}$ of flow rate. The identification and peak assignment of the phenolics were based on comparison of retention times and spectral data with those of the standards. The identified phenolics were quantified according to respective standard calibration curves [15].

\subsubsection{Determination of Fatty Acid Composition}

Fatty acids methyl-esters (FAME) were prepared using methanolic $\mathrm{KOH}$, according to the standard method ISO $5509,(2000)$ [16] from the oil obtained after extraction. The fatty acid profile was determined by gas chromatographic separation of their methyl esters [17] on a capillary column. The temperature of the injector and detector was set at $250^{\circ} \mathrm{C}$. The initial oven temperature was $170^{\circ} \mathrm{C}$. This temperature was maintained for $8 \mathrm{~min}$, and then increased at a rate of $2^{\circ} \mathrm{C}$ min- 1 to $190^{\circ} \mathrm{C}$, which was held for $7 \mathrm{~min}$. Helium was used as the carrier gas at a flow rate of $0.87 \mathrm{~mL}$ min-1 and injection volume was $0.3 \mu \mathrm{L}$. The fatty acid composition is expressed as weight percentage of total (internal normalization method).

\subsubsection{Preparation of Basal Diet}

The used basal diet consisted of the following components of AIN-93M diet according to Reeves et al., (1993) [18].

\subsubsection{Induction of Hypercholesterolemia}

Hypercholesterolemia was Induced by adding $1 \%$ cholesterol powder with $0.5 \%$ bile salt to the diet for 8 weeks [19].

\subsection{Biological Study}

Animals ( $\mathrm{n}=35)$ were fed on basal diet for one week for adaptation. After this week animals were divided into 5 groups and 7 rats in each group. Group 1 was fed on basal diet as a negative (- ve) control, group 2 was fed on basal diet with $4 \%$ GSO instead of soy oil as -ve control of (GSO), group 3 was fed on high cholesterol diet (HCD) as a positive (+ ve) control, group $4(2 \%$ GSO $)$ was fed on high cholesterol diet (HCD) with $2 \%$ GSO and group 5 (4\% GSO) was fed on high cholesterol diet (HCD) with 4\% GSO.

During the experimental period, water and diet were introduced Ad-Libitum. At the end of experiment (8 weeks), rats were fasted over night before scarifying. Blood were collected then centrifuged to obtain serum for biochemical analysis. Heart, liver and aorta were removed from each rat to histopathological examination.

\subsection{Biochemical Analysis}

Determination of serum cholesterol according to the method of Naito, $\left(1984_{a}\right.$ ) [20], serum Triglyceride according to the method of Fossati and Prencipe, (1982) [21]. Serum HDL-C was determined by the method of Grove, (1979) [22]; Naito, $\left(1984_{b}\right.$ ) [23]. LDL-cholesterol was calculated by Friedewald et al., (1972) [24] formula as following: LDL-C = Total cholesterol - HDL-C - (TG/5). Serum VLDLcholesterol was calculated according to Friedewald et al., (1972) [24] equation: VLDL-C concentration $(\mathrm{mg} / \mathrm{dl})=$ (Triglyceride/5). Determination of aspartate aminotransferase 
(AST) by IFCC, (1976) [25] method. Determination of Alanine Aminotransferase (ALT) according to (IFCC, 1980) [26] method. Alkaline Phosphatase (ALP) GSCC, (1972) [27] method. Determination of Malondialdehyde (MDA) according to Satoh, (1978) [28]; and Ohkawa et al., (1979) [29]. Glutathione S-transferases (GST) according to Habig et al., (1974) [30]; Mannervik et al., (1988) [31].

\subsection{The Atherogenic Indices Were Calculated as Follows}

- Cardiac Risk Ratio (CRR) = TC/HDL-C

- LDL-C to HDL-C ratio = LDL/HDL

- Atherogenic Coefficient $(\mathrm{AC})=(\mathrm{TC}-\mathrm{HDLC}) / \mathrm{HDL}-\mathrm{C}$

- Atherogenic Index of Plasma (AIP) $=\log (\mathrm{TG} / \mathrm{HDL}-\mathrm{C})$ [32].

\subsection{Histopathological Examination}

Autopsy samples were taken from the liver, heart and aorta of rats in different groups and fixed in $10 \%$ formal saline for twenty-four hours. Washing was done in tap water then serial dilutions of alcohol (methyl, ethyl and absolute ethyl) were used for dehydration. Specimens were cleared in xylene and embedded in paraffin at $56^{\circ}$ in hot air oven for twenty-four hours. Paraffin bees wax tissue blocks were prepared for sectioning at 4 microns' thickness by sledge microtome. The obtained tissue sections were collected on glass slides, deparaffinized, and stained by hematoxylin and eosin stain for examination through the light electric microscope [33].

\subsection{Statistical Analysis}

Statistical analysis was carried out using analysis of variance (ANOVA) test with the statistical analysis system, [34]. Results were expressed as mean $\pm \mathrm{SD}$ at $\mathrm{P}<0.05$ significance.

\section{Results}

Table 1 shows Phenolic compounds in grape seed oil. A total of 25 phenolic compounds identified in GSO. The analysis of phenolic acids $(\mu / 100 \mathrm{~g})$ of GSO showed that the benzoic acid, e-vanillic acid, iso-ferulic, P-OH-benzoic, protocatchuic, caffeine, vanillic acid, epicatechein and catechol were the major phenolic acid in GSO. Also, GSO showed high content of 3-hydroxy tyrosol, Pyrogallol, Salicylic, Catechein, cinnamic acid, caffeic acid and chlorogenic acid. While, coumarin $28.73 \mathrm{mg} / 100 \mathrm{~g}, 3$, 4, 5methoxy-cinnamic $23.57 \mathrm{mg} / 100 \mathrm{~g}$, gallic $10.65 \mathrm{mg} / 100 \mathrm{~g}$, 4amino-benzoic $10.09 \mathrm{mg} / 100 \mathrm{~g}$ and Resveratrol $4.67 \mathrm{mg} / 100 \mathrm{~g}$ were found to be the lowest phenolic compound concentration.

Table 1. Phenolic compounds of grape seed oil (GSO).

\begin{tabular}{ll}
\hline Phenolic compounds & $\boldsymbol{\mu / 1 0 0 g}$ \\
\hline Gallic & 10.65 \\
Pyrogallol & 88.62 \\
3-hydroxy tyrosol & 91.04 \\
4-Amino-benzoic & 10.09 \\
Protocatchuic & 214.17 \\
\hline
\end{tabular}

\begin{tabular}{ll}
\hline Phenolic compounds & $\boldsymbol{\mu / 1 0 0 g}$ \\
\hline Chlorogenic & 40.24 \\
Catechol & 95.12 \\
Epicatechin & 98.55 \\
Catechin & 61.54 \\
Caffeine & 127.13 \\
3, 4, 5-methoxy-cinnamic & 23.57 \\
Coumarin & 28.73 \\
Salicylic & 81.88 \\
P-OH-benzoic & 228.43 \\
Caffeic & 51.38 \\
Vanillic & 115.04 \\
Ferulic & 31.46 \\
Iso-ferulic & 254.94 \\
e- vanillic & 544.44 \\
Resveratrol & 4.67 \\
Ellagic & 46.29 \\
Alpha-coumaric & 30.06 \\
Benzoic & 717.33 \\
p-coumaric & 37.94 \\
Cinnamic & 52.16 \\
\hline
\end{tabular}

Table 2 shows the fatty acid compositions of grape seed oil. The fatty acids composition in GSO demonstrated that the saturated fatty acids SFA was $16.24 \%$. Palmitic acid (C16:0) 10.86\% and Stearic acid (C18:0) 4.5\% were the main fatty acids of the total SFA. Oleic acid (C18:1) was the major component of monounsaturated fatty acid MUFA by $22.12 \%$ of total $23.50 \%$ MUFA. However, polyunsaturated fatty acid PUFA was the major content of the total fatty acids of GSO consist of $60.54 \%$ and represented in Linoleic acid (C18:2) 53.12, $\alpha$-Linolenic acid (C18:3n3) 6.37 and linoelaidic acid (C18:3n6) 1.05\%.

Table 2. Fatty acid compositions of grape seed oil (GSO).

\begin{tabular}{ll}
\hline Fatty acids & \% \\
\hline $\mathrm{C} 16: 0$ & 10.86 \\
$\mathrm{C} 16: 1$ & 0.12 \\
$\mathrm{C} 17: 0$ & 0.12 \\
$\mathrm{C} 17: 1$ & 0.06 \\
$\mathrm{C} 18: 0$ & 4.5 \\
$\mathrm{C} 18: 1$ & 22.12 \\
$\mathrm{C} 18: 2$ & 53.12 \\
$\mathrm{C} 18: 3 \mathrm{n} 6$ & 1.05 \\
$\mathrm{C} 18: 3 \mathrm{n} 3$ & 6.37 \\
$\mathrm{C} 20: 0$ & 0.34 \\
$\mathrm{C} 20: 1$ & 0.2 \\
$\mathrm{C} 22: 0$ & 0.33 \\
$\mathrm{C} 24: 0$ & 0.09 \\
\hline
\end{tabular}

\subsection{Effect of Grape Seed Oil on Blood Lipids}

The effect of grape seed oil (GSO) on serum total cholesterol (TC), triglyceride (TG), HDL-cholesterol, LDLcholesterol and VLDL of rats was illustrated in table 3. Regarding to the results of serum total cholesterol indicated significant increase in the +ve control group compared with ve control group $168.04 \pm 20.98$ and $114.06 \pm 6.38 \mathrm{mg} / \mathrm{dl}$, respectively. Whilst, significant improvement was recorded in the level of TC of 4\% GSO group which decreased to be $141.46 \pm 12.30 \mathrm{mg} / \mathrm{dl}$. But, the TC level of $2 \%$ GSO group decreased with non-significant difference. However, nonsignificant difference was recorded in the GSO (-ve) 
compared with -ve control. However, the level of serum triglyceride of $+v e$ control group showed significant increase compared with -ve control group with the mean values of $235.22 \pm 22.25$ and $153.10 \pm 7.01 \mathrm{mg} / \mathrm{dl}$, respectively. However, the level of TG in $2 \%$ GSO and $4 \%$ GSO decreased significantly to be $196.95 \pm 11.35 \mathrm{mg} / \mathrm{dl}$, and $205.70 \pm 8.66 \mathrm{mg} / \mathrm{dl}$ respectively Table 3 .

In the case of high density lipoprotein (HDL); the level of serum HDL in the +ve control group decreased significantly $(\mathrm{P}<0.05)$ compared with -ve control. While, consuming of $2 \%$ and $4 \%$ GSO with HCD led to significant increase $(\mathrm{P}<$ $0.05)$ in HDL level compared with +ve control group $58.28 \pm 10.29$ and $70.94 \pm 12.25 \mathrm{mg} / \mathrm{dl}$, respectively. However, the level of HDL of GSO (-ve) showed significant increase compared with -ve control. Concerning with LDL level the mean value of + ve control group increased significantly to be
$81.16 \pm 16.77 \mathrm{mg} / \mathrm{dl}$, compared with -ve control group $33.22 \pm 5.31 \mathrm{mg} / \mathrm{dl}$. However, great improvement in the LDL level was recorded in 4\% GSO which decreased significantly compared with +ve control $31.77 \pm 6.82 \mathrm{mg} / \mathrm{dl}$. Furthermore, LDL level of $2 \%$ GSO decreased significantly compared with + ve control groups with the mean values of $48.71 \pm 8.49$ $\mathrm{mg} / \mathrm{dl}$. Otherwise, the level of LDL of GSO (-ve) group decreased significantly compared with -ve control. In relation of serum very low density lipoprotein (VLDL) level, similar findings of triglyceride result fundamentally recorded in VLDL results. Subsequently, the level of VLDL of +ve control group increased significantly compared with -ve control group. While, the level of VLDL of $2 \%$ and $4 \%$ GSO group decreased significantly compared with +ve control group Table 3.

Table 3. Effect of grape seed oil (GSO) on serum total cholesterol (TC), triglyceride (TG), HDL-cholesterol, LDL-cholesterol and VLDL of rats.

\begin{tabular}{llllll}
\hline \multirow{2}{*}{ Groups } & Total Cholesterol (TC) & Triglyceride (TG) & HDL-C & LDL-C & VLDL \\
\cline { 2 - 6 } & $(\mathbf{m g} / \mathbf{d l})$ & $153.10 \pm 7.01^{\mathrm{c}}$ & $50.24 \pm 5.70^{\mathrm{b}}$ & $33.22 \pm 5.31^{\mathrm{c}}$ & $30.60 \pm 1.40^{\mathrm{c}}$ \\
\hline -ve & $114.06 \pm 6.38^{\mathrm{c}}$ & $146.39 \pm 9.87^{\mathrm{c}}$ & $69.16 \pm 10.45^{\mathrm{a}}$ & $23.04 \pm 4.43^{\mathrm{d}}$ & $29.28 \pm 1.97^{\mathrm{c}}$ \\
GSO (-ve) & $121.48 \pm 7.35^{\mathrm{c}}$ & $235.22 \pm 22.25^{\mathrm{a}}$ & $39.85 \pm 3.87^{\mathrm{c}}$ & $81.16 \pm 16.77^{\mathrm{a}}$ & $47.04 \pm 4.45^{\mathrm{a}}$ \\
+ve & $168.04 \pm 20.98^{\mathrm{a}}$ & $196.95 \pm 11.35^{\mathrm{b}}$ & $63.04 \pm 5.80^{\mathrm{a}}$ & $48.71 \pm 8.49^{\mathrm{b}}$ & $39.38 \pm 2.27^{\mathrm{b}}$ \\
2\% GSO & $151.14 \pm 13.16^{\mathrm{ab}}$ & $205.70 \pm 8.66^{\mathrm{b}}$ & $68.55 \pm 11.02^{\mathrm{a}}$ & $31.77 \pm 6.82^{\mathrm{c}}$ & $41.14 \pm 1.73^{\mathrm{b}}$ \\
\hline$\%$ GSO & $141.46 \pm 12.30^{\mathrm{b}}$ & &
\end{tabular}

All values represented as mean $\pm \mathrm{SD}$.

Means with different superscript are significantly different $(\mathrm{P}<0.05)$.

\subsection{Effect of Grape Seed Oil on Lipid Ratios}

Table 4 shows the results of atherogenic coefficient (AC); the AC of +ve control group showed significant increase ( $\mathrm{P}$ $<0.05)$ compared with -ve control group. While, significant decreased $(\mathrm{P}<0.05)$ was found in all other groups compared with +ve control group. Meanwhile, GSO (-ve) decreased significantly compared with -ve control group. Similarly, to atherogenic coefficient (AC), the results of cardiac risk ratio (CRR) showed significant increase $(\mathrm{P}<$ $0.05)$ in +ve control group compared with -ve control group. Furthermore, the CRR of $2 \%$ and $4 \%$ GSO groups decreased significantly $(\mathrm{P}<0.05)$ compared with +ve control. Also, the CRR of GSO (-ve) decreased significantly compared with -ve control.

Table 4. Effect of grape seed oil (GSO) on lipid ratios: atherogenic coefficient $(A C)$, cardiac risk ratio (CRR), LDL-c to $H D L-c$ ratio and atherogenic index of plasma (AIP) of rats.

\begin{tabular}{|c|c|c|c|c|}
\hline \multirow{2}{*}{ Groups } & \multicolumn{4}{|l|}{ Lipid ratios } \\
\hline & $\mathrm{AC}$ & CRR & LDL/ HDL & AIP \\
\hline -ve & $1.29 \pm 0.27^{\mathrm{bc}}$ & $2.29 \pm 0.27^{\mathrm{bc}}$ & $0.70 \pm 0.20^{b}$ & $0.50 \pm 0.02^{b}$ \\
\hline GSO (-ve) & $0.78 \pm 0.24^{\mathrm{c}}$ & $1.78 \pm 0.23^{c}$ & $0.35 \pm 0.18^{b}$ & $0.33 \pm 0.08^{c}$ \\
\hline$+\mathrm{ve}$ & $3.23 \pm 0.68^{\mathrm{a}}$ & $4.23 \pm 0.68^{\mathrm{a}}$ & $2.05 \pm 0.39^{\mathrm{a}}$ & $0.74 \pm 0.06^{\mathrm{a}}$ \\
\hline $2 \% \mathrm{GSO}$ & $1.41 \pm 0.36^{\mathrm{b}}$ & $2.41 \pm 0.35^{\mathrm{b}}$ & $0.76 \pm 0.07^{b}$ & $0.47 \pm 0.07^{b}$ \\
\hline $4 \% \mathrm{GSO}$ & $1.09 \pm 0.25^{\mathrm{bc}}$ & $2.09 \pm 0.25^{\mathrm{bc}}$ & $0.48 \pm 0.18^{b}$ & $0.48 \pm 0.06^{\mathrm{b}}$ \\
\hline
\end{tabular}

All values represented as mean $\pm \mathrm{SD}$.

Means with different superscript are significantly different $(\mathrm{P}<0.05)$.
Regarding to the results of LDL-c to HDL-c ratio, +ve control group significantly higher $(\mathrm{P}<0.05)$ than -ve control group. However, the mean values of all other groups decreased significantly compared with +ve control group. Moreover, the GSO (-ve) showed significant decrease compared with -ve control group. In concerning with, the results of atherogenic index of plasma (AIP), the +ve control showed significantly higher than -ve control group $0.74 \pm 0.06$ and $0.50 \pm 0.02$, respectively. Whereas, the AIP ratio of $2 \%$ and $4 \%$ GSO decreased significantly compared with +ve control group. Also, the AIP ratio of GSO (-ve) $(0.33 \pm 0.08)$ reduced significantly than -ve control as indicated in Table 4.

\subsection{Effect of Grape Seed Oil on Liver Function}

The level of serum aspartate amino transferase (AST) of the +ve control group increased significantly compared with the ve control group $129.26 \pm 19.59$ and $187.68 \pm 20.53 \mathrm{U} / \mathrm{L}$, respectively. However, 4\% GSO caused significant decrease $(\mathrm{P}<0.05)$ in serum AST compared with +ve control, whereas, the AST level of $2 \%$ GSO decreased without significant difference. However, AST level of GSO (-ve) group showed non-significant difference compared with -ve control. Regarding to the results of serum ALT, high cholesterol diet caused significant increase $(\mathrm{P}<0.05)$ in the +ve control compared with -ve control. Whilst, the serum ALT of $2 \%$ and 4\% GSO group decreased significantly compared with +ve control group. However, the ALT level of GSO (-ve) showed non-significant difference compared with -ve control group 
16.52 $\pm 4.94 \mathrm{U} / \mathrm{L}$. In concerning with serum alkaline phosphatase (ALP) the results showed significant increase $(\mathrm{P}<0.05)$ in the +ve control group compared with all other groups. Meanwhile, GSO 2\% and 4\% reduced the ALP level. Also, non-significant difference was recorded in the GSO (-ve) compared with -ve control group as indicated in Table 5.

Table 5. Effect of grape seed oil (GSO) on serum aspartate amino transferase (AST), alanine amino transferase (ALT) and alkaline phosphatase (ALP) of rats.

\begin{tabular}{llll}
\hline \multirow{2}{*}{ Groups } & AST & ALT & ALP \\
\cline { 2 - 4 } & $(\mathbf{U} / \mathbf{L})$ & & \\
\hline -ve & $129.26 \pm 19.59^{\mathrm{b}}$ & $13.60 \pm 2.58^{\mathrm{c}}$ & $341.62 \pm 23.00^{\mathrm{c}}$ \\
GSO (-ve) & $131.22 \pm 8.04^{\mathrm{b}}$ & $16.52 \pm 4.94^{\mathrm{bc}}$ & $316.58 \pm 30.50^{\mathrm{c}}$ \\
$+\mathrm{ve}$ & $187.68 \pm 20.53^{\mathrm{a}}$ & $29.37 \pm 6.79^{\mathrm{a}}$ & $684.94 \pm 63.52^{\mathrm{a}}$ \\
$2 \%$ GSO & $148.30 \pm 5.74^{\mathrm{ab}}$ & $22.18 \pm 2.49^{\mathrm{b}}$ & $463.70 \pm 29.73^{\mathrm{b}}$ \\
\hline 4\% GSO & $142.52 \pm 12.14^{\mathrm{b}}$ & $17.12 \pm 1.92^{\mathrm{bc}}$ & $447.14 \pm 34.69^{\mathrm{b}}$ \\
\hline
\end{tabular}

All values represented as mean $\pm \mathrm{SD}$.

Means with different superscript are significantly different $(\mathrm{P}<0.05)$.

\subsection{Effect of Grape Seed Oil on Oxidation and Antioxidant Biomarkers}

Table 6. Effect of grape seed oil (GSO) on serum malondialdehyde (MDA) and serum glutathione transferase (GST) of rats.

\begin{tabular}{l|l|l}
\hline Groups & $\begin{array}{l}\text { Malondialdehyde } \\
(\mathbf{n m o l} / \mathbf{m l})\end{array}$ & $\begin{array}{l}\text { Glutathione-S- } \\
\text { Transferase }(\mathbf{m g} / \mathbf{d l})\end{array}$ \\
\hline -ve & $3.56 \pm 0.41^{\mathrm{ab}}$ & $203.27 \pm 14.09^{\mathrm{b}}$ \\
\hline GSO (-ve) & $2.95 \pm 0.37^{\mathrm{c}}$ & $253.83 \pm 21.64^{\mathrm{a}}$ \\
\hline $\mathrm{ve}$ & $4.07 \pm 0.16^{\mathrm{a}}$ & $114.28 \pm 17.07^{\mathrm{c}}$ \\
\hline $2 \%$ GSO & $3.63 \pm 0.60^{\mathrm{ab}}$ & $171.34 \pm 16.48^{\mathrm{b}}$ \\
\hline $4 \%$ GSO & $3.23 \pm 0.23^{\mathrm{bc}}$ & $206.95 \pm 20.73^{\mathrm{b}}$ \\
\hline
\end{tabular}

All values represented as mean $\pm \mathrm{SD}$.

Means with different superscript are significantly different $(\mathrm{P}<0.05)$.

Regrading to serum MDA, the 4\% GSO decreased the MDA level significantly compared with +ve control group, while, the $2 \%$ GSO decrease slightly. However, the level of serum MDA of GSO (-ve) decreased significantly compared with -ve control group. In relation to serum glutathione-stransferase (GST), the 4\% GSO caused significant increase in the GST level to be $206.95 \pm 20.73 \mathrm{mg} / \mathrm{dl}$ compared with the + ve control group $114.28 \pm 17.07 \mathrm{mg} / \mathrm{dl}$. Also, the level of serum GST of the $2 \%$ GSO increased significantly compared with +ve control group. While, the highest level of serum GST was recorded in GSO (-ve) $253.83 \pm 21.64 \mathrm{mg} / \mathrm{dl}$ Table 6 .

\section{Histopathological Examination}

Histopathological examination of the liver of rats from (ve) control group showed no histopathological changes of the hepatocytes and central vein as shown in (Fig. 1). However, liver of rat from GSO (-ve) group revealed normal histopathological structure (Fig. 2). Meanwhile, the liver of rat from +ve control group revealed a severe fatty change represents all over the hepatocytes (Fig. 3). Whereas, liver of rat from $2 \%$ GSO group revealed a severe fatty change in diffuse manner all over the hepatocytes as shown in (Fig. 4). Meanwhile, liver of rat from 4\% GSO group showed moderate steatosis in hepatocytes adjacent the hepatic central vein (Fig. 5).

Regarding to histopathological examination of heart, the results revealed that a normal histopathological structure in the heart of rat from -ve control group as shown in (Fig. 6). Whereas, heart of rat from +ve control group showed sever focal inflammatory cells infiltration in the degenerated myocardial bundles (Fig. 7). However, heart of rat from all other groups revealed no histopathological alteration in myocardium as shown in (Figs. $8-10$ ). Histopathological examination of the aorta of rat from -ve control group showed no histopathological alteration in the tunica intima, media and adventitia (Fig. 11). Also, aorta of rat from RBO and GSO (-ve) groups showed normal histopathological structure (Fig. 12). while, aorta of rat from +ve control group revealed a sever vacuolization in the tunica media (Fig. 13). However, aorta of rat from $2 \%$ and $4 \%$ GSO groups showed mild vacuolization in the tunica media as shown in (Figs. 14 and 15).

Table 7. Effect of grape seed oil (GSO) on the histopathological alteration of the liver, heart and aorta of rats.

\begin{tabular}{llll}
\hline Organs & Liver & Heart & Aorta \\
\hline Histopathological Alterations & Fatty change in hepatocytes & $\begin{array}{l}\text { Degeneration and inflammatory } \\
\text { reaction in myocardial }\end{array}$ & Vacuolization in tunica media \\
\hline -ve & - & - & - \\
GSO (-ve) & - & - & +++ \\
$+\mathrm{ve}$ & +++ & - & - \\
$2 \%$ GSO & +++ & - & ++ \\
$4 \%$ GSO & ++ & + \\
\hline
\end{tabular}

$-=$ nil $+=$ mild $++=$ moderate $+++=$ severe 


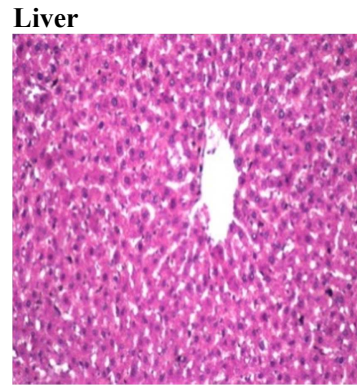

Fig. 1. Liver of rat from -ve control group showing no histopathological change in the central vein and surrounding hepatocytes. Heart

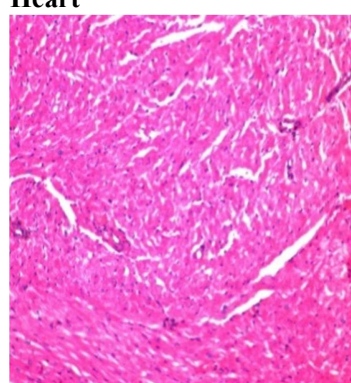

Fig. 6. Heart of rat from -ve control group showing no histopathological alteration.

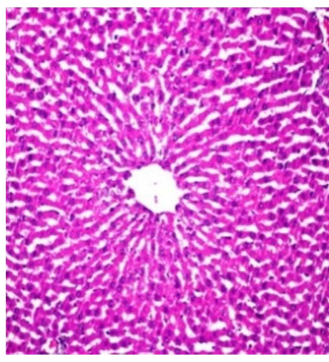

Fig. 2. Liver of rat from GSO (-ve) group showing no histopathological alteration.

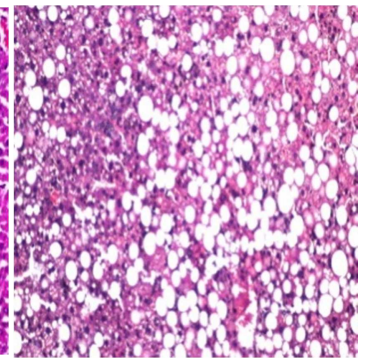

Fig. 3. Liver of rat from + ve control group showing severe fatty change represents all over the hepatocytes.

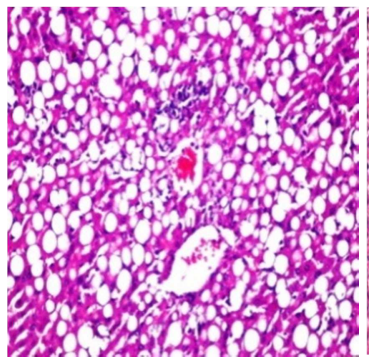

Fig. 4. Liver of rat from $2 \%$ GSO group showing severe fatty change in diffuse manner all over the hepatocytes.

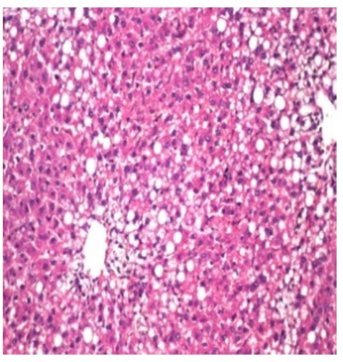

Fig. 5. Liver of rat from $4 \%$ GSO group showing moderate steatosis in hepatocytes adjacent the hepatic central vein.

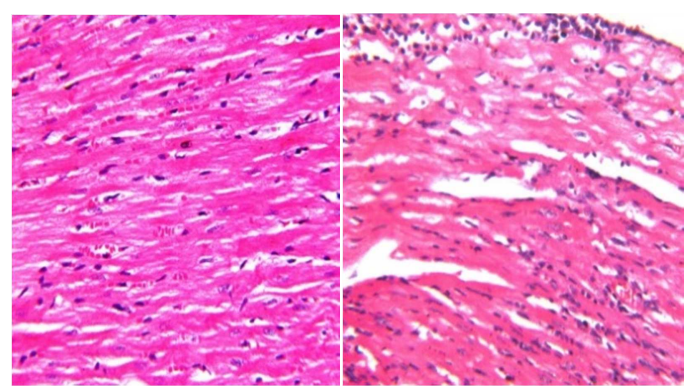

Fig. 7. Heart of rat from GSO (-ve) group showing no histopathological alteration.
Fig. 8. Heart of rat from +ve control group showing sever focal inflammatory cells infiltration in the degenerated myocardial bundles.

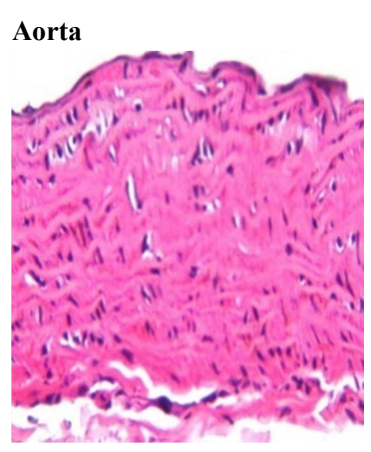

Fig. 11. Aorta of rat from -ve control group showing no histopathological alteration in the tunica intima, media and adventitia.

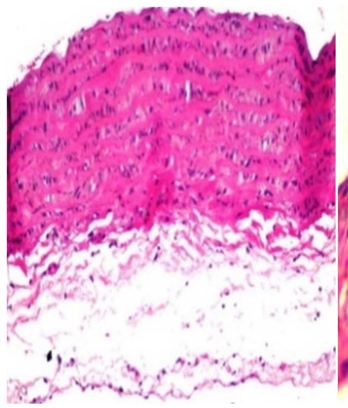

Fig. 12. Aorta of rat from GSO (-ve) group showing no histopathological alternation.

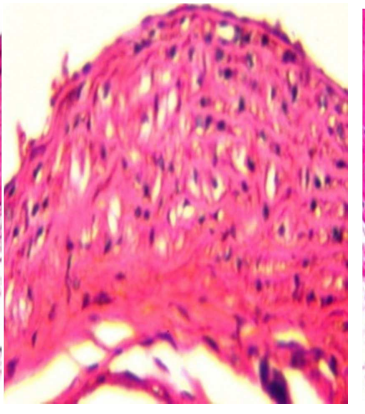

Fig. 13. Aorta of rat from +ve control group showing sever vacuolization in the tunica media.

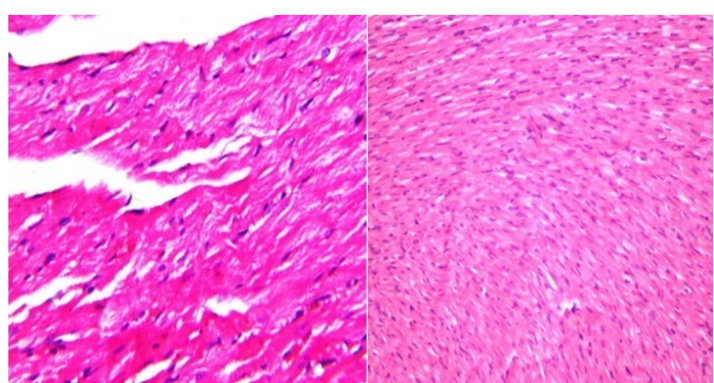

Fig. 9. Heart of rat from $2 \%$ GSO group showing no histopathological alteration.
Fig. 10. Heart of rat from $4 \%$ GSO group showing no histopathological changes.

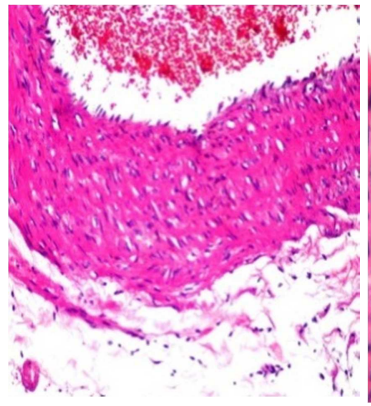

Fig. 14. Aorta of rat from $2 \%$ Fig. 15. Aorta of rat from GSO group showing mild vacuolization in the tunica media.

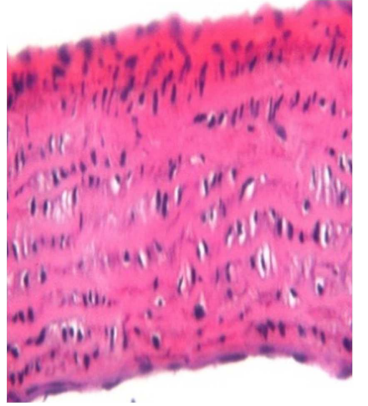

4\% GSO group showing mild vacuolization in the tunica media.

\section{Discussion}

Hypercholesterolemia is associated with the oxidative stress which induced by the production of reactive oxygen species and/or decreased the antioxidant system causing several diseases, including coronary heart disease and atherosclerosis. Researchers have identified risk factors that are highly correlated to the development of CVD [35]. Moreover, the common type of hypercholesterolemia is familial hypercholesterolemia, which occurs in about 1 of 500 people [36]. Familial hypercholesterolemia (FH) is a genetic disease leading to elevated the level of LDLcholesterol and increased the risk of premature myocardial infarction (MI). Therefore, FH may explain about $20 \%$ of familial cases with premature coronary heart disease (CHD) [37]. FH is caused by deficient of low-density lipoprotein (LDL) receptors, leading to a reduced in LDL uptake cholesterol by the liver. So, cases with FH have a high risk of 102 cardiovascular disease (CVD), especially coronary heart disease [38].

The results of the present indicated that the diet containing GSO decreased significantly $(\mathrm{P}<0.05)$ Serum TC, TG, LDL$\mathrm{C}$ levels and increased serum HDL-C $(\mathrm{P}<0.05)$. This results compatible with the results of Chung et al., (2003) [39], who reported that GSO and/or isoflavone have important role for improvement of serum lipid profile. Moreover, the study of Nash, (2004) [40], reported that 45g of grape seed oil per day 
may increase HDL-cholesterol and reduce LDL-cholesterol, thus it helping to prevent heart disease. Furthermore, GSO improve the lipid ratios: atherogenic coefficient (AC), cardiac risk ratio (CRR), LDL-c to HDL-c ratio and atherogenic index of plasma (AIP) compared with the +ve control group. This results confirmed with Kim et al., (2010) [6], who reported that the GSO decreased serum TC, LDL-c significantly. Also, atherogenic index and HDL:TC ratio were enhanced significantly. Also, GSO play an important role in lipid metabolism [41], besides enhancing oxidative stress and improving serum lipid profile [7].

The results of the present study showed that the HCD caused significant increase $(\mathrm{P}<0.05)$ in the liver enzymes level AST, ALT and ALP. However, GSO caused significant decrease $(\mathrm{P}<0.05)$ in serum AST, ALT and ALP as shown in Table 5. The GSO reduced liver enzymes because its antioxidant properties. Several studies suggested the grape seed oil has hepatoprotective properties as the study of Maheswari and Rao, (2005) [42], who reported that the GSO decreased liver enzymes. Also, the results of the study of Khudair and Aldabaj, (2015) [43], found that the oral administration of GSO with sodium fluoride water showed significant reduction in serum AST and ALP.

The results of this study showed that the GSO caused significant decrease $(\mathrm{P}<0.05)$ in the serum MDA level compared with $+v e$ control group, in addition to significant increase in the GST level. This results due in part to the antioxidant activity of GSO. GSO is a good source of important bioactive components such as phenolics and antioxidants, which decrease oxidative stress that contributes to the hepatotoxicity [9]. These results agree with Maheswari and Rao, (2005) [42], who found significant decreased in MDA and significant improvement in liver glutathione, superoxide dismutase by oral administration of GSO for 7 days. Also, Ismail et al., (2015) [44], reported that the GSO act as a potent antioxidant its act to scavenge the free radicals, improve the antioxidant and suppress the inflammatory responses enzymes activity.

The histopathological examination of liver showed fatty liver in all rats fed a high-cholesterol diet, the abnormalities fatty changes in the liver due to the daily accumulation of cholesterol in the liver. Kwok et al., (2010) [45], reported that the development of fatty liver, an increased nitric oxide synthase (NOS) activity and an elevated oxidative stress (as estimated by the attenuated levels of anti-oxidant enzymes) associated with HCD. Our results indicated that the 4\% GSO decreased the fatty changes slightly. However, the results of histopathological examination of heart and aorta showed the ability of GSO to protect heart and liver against hypercholesterolemia. This study suggests that the GSO able to protect against the risk of CVD.

\section{Conclusion}

In conclusion, this study demonstrated that the grape seed improved blood lipids and atherogenic lipid profile in hypercholesterolemic rats. This effect may be attributed to the high percentage of free fatty acids and anti-oxidant activity of GSO. Therefore, the GSO effective to decrease cardiovascular risk.

\section{References}

[1] Abdulrahman N., Abbas L., Darweesh H., Aref A., Ahmed M., Babaker M. et al., (2013): Effect of grape seed on some blood parameters and serum components of common CARP J Food Industries and Nutr. Sci. 3: 169-174.

[2] Matthaus B. (2008): Virgin grape seed oil: Is it really a nutritional highlight? Eur. J. Lipid Sci. Technol. 110: 645-650.

[3] Fernandes L., Casal S., Cruz R., Pereira J. and Ramalhosa E. (2013): Seed oils of ten traditional Portuguese grape varieties with interesting chemical and antioxidant properties. Food Research International. 50: 161-166.

[4] Bail S., Stuebiger G., Krist S., Unterweger H. and Buchbauer G. (2008): Characterisation of various grape seed oils by volatile compounds, triacylglycerol composition, total phenols and antioxidant capacity. Food Chemistry. 108: 1122-1132.

[5] Bravi M., Spinoglio F., Verdone N., Adami M., Aliboni A., D'Andrea A. et al., (2007): Improving the extraction of $\alpha$ tocopherol-enriched oil from grape seeds by supercritical $\mathrm{CO}_{2}$. Optimisation of the extraction conditions. J Food Engineering. 78: 488-493.

[6] Kim D., Jeon G., Sung J., Oh S., Hong H. and Lee J. (2010): Effect of grape seed oil supplementation on plasma lipid profiles in rats. Food Sci Biotechnol. 19 (1): 249-252.

[7] Ranjbar-Zahedani M., Alinejad N., Zadeh S. and Mazloom Z. (2015): Comparison of the effects of edible oils: rice bran, grape seed, and canola on serum lipid profile and paraoxonase activity in hyperlipidemic rats. Int Cardiovasc Res J. 9 (1): 28-33.

[8] Pilehvar A., Tabrizi B. and Javadi A. (2013): The effect of grape seeds oil on lipid content of serum in rats. Adv. Biores. 4: $21-25$.

[9] Wang Z., Zhang Z., Du N., Wang K. and Li L. (2015): Hepatoprotective Effects of grape seed procyanidin $B_{2}$ in rats with carbon tetrachloride-induced hepatic fibrosis. Altern Ther Health Med. 2: 12-21.

[10] Pardo J., Fernandez E., Rubio M., Alvarruiz A. and Alonso G. (2009): Characterization of grape seed oil from different grape varieties (Vitis vinifera). Eur J Lipid Sci Technol. 111: 188193.

[11] Irandoost P., Ebrahimi M., and Pirouzpanah S. (2013): Does grape seed oil improve inflammation and insulin resistance in overweight or obese women? Int J Food Sci Nutr. 64 (6): 706710.

[12] Lai X., Kang X., Zeng L., Li J., Yang Y. and Liu D. (2014): The protective effects and genetic pathways of thorn grape seeds oil against high glucoseinduced apoptosis in pancreatic $\beta$-cells. Complementary and Alternative Medicine. 14: 10.

[13] Javadi S., Eftekhari A. and Farshid A. (2014): The effects of grape seed oil on histopathological changes of the pancreas, liver and plasma lipids in streptozotocin induced diabetic rats. The J Urmia University of Medical Sciences. 25 (7): 606-615. 
[14] Gómez A. M., Pereyra L. C. and Martínez E. (1996): Chem. Eng. J. 61: 227.

[15] Hatzidimitriou E., Nenadis N. and Tsimidou M. Z. (2007): Changes in the catechin and epicatechin content of grape seeds on storage under different water activity (aw) conditions. Food Chemistry 105: 1504-1511.

[16] ISO 5509, (2000): Animal and vegetable fats and oils Preparation of methyl esters of fatty acids. International Standard Organization, Geneva (Switzerland).

[17] ISO 5508, (1990): Animal and vegetable fats and oils Analysis by gas chromatography of methyl esters of fatty acids. International Standard Organization, Geneva (Switzerland).

[18] Reeves P. G., Nielsen F. H. and Fahmy G. G. (1993): AIN-93. Purified diets for laboratory rodents: Final report of the American Institute of Nutrition adhoc wriling committee on the reformulation of the AIN-76 A Rodent diet. J. Nutrition. 123: $1939-151$.

[19] Takako Y., Eun Ju C., Sumiyo S., Akiko S., Takuya O. and Yasuo S. (2006): The Protective Role of Chinese Prescription Kangen-karyu Extract on Diet-Induced Hypercholesterolemia in Rats. Biol. Pharm. Bull. 29 (4): 760-765.

[20] Naito H. K. (1984a): Cholesterol. Kaplan A et al., Clin Chem The C. V. Mosby Co. St Louis. Toronto. Princeton; 119411206 and 437.

[21] Fossati P. and Prencipe L. (1982): Serum triglycerides determined colorimetrically with an enzyme that produces hydrogen peroxide. Clin. Chem 28 (10): 2077-2080.

[22] Grove T. H. (1979): Effect of reagent $\mathrm{pH}$ on Determination of HDL Cholesterol by precipitation with Sodium Phosphotungstate-magnesium Clin Chem 25: 560-561.

[23] Naito H. K. (1984b): High-density lipoprotein (HDL) cholesterol. Kaplan A et al. Clin Chem. The C. V. Mosby Co. St Louis. Toronto. Princeton 1207-1213 and 437.

[24] Friedewald W. T., Levy R. I. and Fredrickson D. S. (1972): Estimation of the concentration of low-density lipoprotein cholesterol in plasma, without use of the preparative ultracentrifuge. Clin. Chem. 18: 499-502.

[25] IFCC, (1976): Expert Panel of Enzymes of the International Federation of Clinical Chemistry, Clin. Chem. Acta. 70: 1942.

[26] IFCC, (1980): Expert Panel of Enzymes of the International Federation of Clinical Chemistry, Clin. Chem. Acta. 105: 147172.

[27] GSCC, (1972): German Society of Clinical Chemistry Standard method for determination Alkaline Phosphatase (AP) activity. J. Clin. Chem. Clin. Biochem. 10: 290.

[28] Satoh K. (1978): Serum lipid peroxide in cerebrovascular disorders determined by a new colorimetric method. Clin, Chem. Acta. 90: 37-43.

[29] Ohkawa H., Hishi W. and Yagi K. (1979): Assay for lipid peroxide in animal tissues by Thiobarbituric acid reaction. Anal. Biochem, 95: 351-358.

[30] Habig W. and Pabst M. and Jakoby W. (1974): Glutathione Stransferase. The first enzymatic step in mercapturic acid formation. J. Biol. Chem. 249: 7130-7139.
[31] Mannervik B. and Danielson U. H. (1988): Glutathione transferases - structure and catalytic activity. CRC Crit. Rev. Biochem. 23: 283-337.

[32] Bhardwaj S. Bhattacharjee J., Bhatnagar M. K. and Tyagi S. (2013): Atherogenic Index of Plasma, CASTELLI Risk Index and Atherogenic Coefficient- New Parameters in Assessing Cardiovascular Risk. IJPBS. 3 (3): 359-364.

[33] Banchroft J. D., Stevens A. and Turner D. R. (1996): Theory and practice of histological techniques, Fourth Ed. Churchil Livingstone, New York, London Can J. Biochem Physiol. 37: 679-686.

[34] SAS, (1996): Statistical Analysis System, User Guide Statistics. SAS Institute Inc. Editors, Cary, NC.

[35] Weiss L. A., Pan L., Abney M. and Ober C. (2006): The sexspecific genetic architecture of quantitative traits in humans. Nat. Genet. 38: 218-222.

[36] Rader D., Cohen J. and Hobbs H. (2003): Monogenic hypercholesterolemia: new insights in pathogenesis and treatment. J Clin Invest. 111: 1795-1803.

[37] Brænne I., Reiz B., Medack A., Kleinecke M., Fischer M., Tuna S., et al., (2014): Whole-exome sequencing in an extended family with myocardial infarction unmasks familial hypercholesterolemia. BMC Cardiovascular Disorders. 14: 108.

[38] Goldstein J. L. and Brown M. S. (2009): The LDL receptor. Arterioscler Thromb Vasc Biol. 29: 431-438.

[39] Chung H., Choe C., Lee J., Park W. and Kang M. (2003): The effect of isoflavone and/or grape seed oil supplementation on blood lipid profiles and bone strength in ovariectomized female rats. Korean J Nutr. 36 (7): 667-674.

[40] Nash D. T. (2004): Cardiovascular risk beyond LDL-C levels: Other lipids are performers in cholesterol story. Postgraduate Medicine. 116: 11-15.

[41] Blu K., Zurabashvili D. Z., Turabelidze D. G., Zurabashvili Z. A. and Giorgobiani I. B. (2012): Fatty acids of grape seed oil and its biological activity as $1.0 \%$ and $2.5 \%$ food-additive. Georgian Med News. 207: 47-50.

[42] Maheswari M. U. and Rao P. G. (2005): Antihepatotoxic effect of grape seed oil in rat. Indian J Pharmacol. 37 (3): 179-182.

[43] Khudair K. and Aldabaj A. (2015): Effect of grape seed oil on hepatic function in adult male rabbits treated with sodium fluoride (Part-II). Advances in Animal and Veterinary Sciences. 3: 550-558.

[44] Ismail A., Moawed F. and Mohamed M. (2015): Protective mechanism of grape seed oil on carbon tetrachloride-induced brain damage in $\gamma$-irradiated rats. J Photochemistry \& Photobiology, B: Biology. 153: 317-323.

[45] Kwok C., Wong C., Yau M. Y., Yu P. H., Shan Au A. L., Poon C. C. et al., (2010): Consumption of dried fruit of Crataegus pinnatifida (hawthorn) suppresses high-cholesterol dietinduced hypercholesterolemia in rats. J of Functional Foods. 2 (3): 179-186. 